\title{
Going beyond the official domain in the search for the culture of employee learning: The case of junior support staff at a South African university
}

\author{
George Mavunga \\ University of Johannesburg \\ Corresponding Author: gmavunga@uj.ac.za
}

(Submitted: 27 March 2019; Accepted: 21 October 2019)

\begin{abstract}
Based on HCT (human capital theory), employee learning and the culture associated with it in South Africa and globally have generally been researched from the perspective of the normative government or employer-initiated policies and programmes. Using Bernstein's (2000) theory of the pedagogic device, this paper suggests the existence of different domains of learning with respect to junior support staff at a South African university. The paper also borrows from critical realism to advocate an approach which asks questions pertaining to the influence of structure and agency on the form of the culture of employee learning in different domains with respect to the junior support staff members. The answers to these questions, the paper suggests, would help with a holistic characterisation of the culture of employee learning associated with this category of employees at the South African university.
\end{abstract}

Key words: Employee learning, culture, domain, institution, higher learning

\section{Introduction}

Employee learning for workers in South Africa and globally, whether they occupy junior or senior positions, is an inescapable imperative for a variety of reasons. These include the need to ensure career development; improve job satisfaction and productivity; keep up with technological developments which are inherent in the 4IR (Fourth Industrial Revolution); fostering teamwork; providing good customer service, and keeping up with competition (Noe, 2013; Hameed and Waheed, 2011). In light of the importance currently being placed on these factors, employee learning is increasingly being seen as a basic human right lack of access to which can, in the long term, be a threat to the very viability of organisations and existence of society (Buckler and Creech, 2014). Indeed, at no historical stage has the impossibility of man to dispense with the continuous acquisition of knowledge and skills been more emphatically laid bare than in this age of 4IR. Stakeholders such as states, civil 
society, and the private sector, therefore, have a responsibility to craft partnerships to ensure the continuous and holistic acquisition of knowledge by all citizens (Young, 2008). Of particular focus should be those citizens in one form of employment or another as their actions impact on, and are also shaped by, the key challenges facing humanity today (Erasmus, et al., 2010). At the same time, a critical question which should be the subject of continuous focus is how this acquisition of knowledge by people in employment can be enhanced for the long-term benefit of society. This is particularly true in South Africa where, especially at junior levels, people do not always secure employment on the basis of their qualifications, skills, or knowledge. Rather, other factors such as one's relationship with the job market also have a bearing on the jobs that many people end up employed in (Allais and Nathan, 2014; Baatjes, 2014).

In South Africa, as a result of the country's past, a large number of employees who occupy junior positions in many organisations still have limited access to learning opportunities which would equip them with the skills on the basis of which they can realise upward career mobility (Naong, 2014). This perpetuates not only workplace inequalities but, to a considerable extent, racialised socio-economic disparities in the country which have been characterised as a negation of the democratic dividend promised in 1994 (Msomi, 2014).

In researching employee learning, especially at junior levels, in many organisations, including higher education institutions, the focus has mainly been on the normative employee learning policies and programmes initiated by governments and employers. Legislation such as the Skills Development Act of 2008, the different National Skills Development Strategies, the establishment of the Sector Education and Training Authorities (SETAs) and Adult Basic Education (ABET) programmes, despite being responsible for some success in terms of enabling employee learning and skills development, have not fully realised their goals (Msomi, 2014). This is attributable to a number of reasons. For example, there is lack of conceptual clarity in terms of what should constitute employee learning (Baatjes, et al., 2014). In addition, the very top-down approach which is adopted in the implementation of worker education, in practice, hardly takes into account the influence of factors such as employees' biographies and identities as well as their individual and collective agency in shaping the form of the culture of employee learning (Hamilton, 2014). This is especially the case with junior employees.

Drawing insights from Bernstein's (2000) theory of the pedagogic device and Critical Realism (CR) (Bhaskar, 2008, 1998, 1989; Mingers, 2014; Vandenberghe, 2014), this article suggests a new conceptualisation of employee learning and the culture associated with it at a South African higher education institution. This is in respect of employees, such as junior administrative assistants in academic and service departments, as well as junior technicians working in technical services. In addition to the competencies directly related to their work, for example, in terms of ICT (information communication technology), such employees are expected to possess soft skills such as customer service and assertiveness. 
On the basis of the proposed conceptualisation of employee learning, the article suggests specific examples of questions which need to be asked to produce data for the purpose of enabling a holistic characterisation of the culture of employee learning at the institution to ensure its enhancement and sustainability. The data which could be produced in this way, the article argues, are usually missing in the top-down approach which continues to be adopted in terms of employee learning strategies in many organisations in South Africa. Consequently, many junior employees in the country continue to face numerous constraints in terms of access to transformative career development opportunities (Naong, 2014). At the same time, the shortcomings in pinning hopes on their capacity for selfeducation continue to be laid bare (Msomi, 2014).

The article begins by defining the culture of employee learning in general. It then discusses the two theories on which the suggested new conceptualisation of the culture of employee learning at the selected South African university is based. These are Bernstein's (2000) theory of the pedagogic device and Critical Realism (CR) (Bhaskar, 2008; Mingers, 2014; Vandenberghe, 2014). This is followed by a discussion of examples of data which can be sought in the official, social, and pedagogic domains at the higher education institution in the search for a holistic characterisation of the culture of employee learning associated with the junior support staff.

\section{The culture of employee learning: Defining the concept}

The culture of employee learning is a complex phenomenon which is still to be fully understood by management and human resource development practitioners in many organisations (Govender, 2009). Harrison (2009: 118) confirms this when, in alluding to the fluidity of the field, he points out that,

Workplace learning and knowledge theory has a multi-disciplinary base and there are no clear-cut boundaries between the various schools of thought, nor is it invariably the case that the most meaningful theories are those produced most recently. We may have more information about 'knowledge' but that does not necessarily mean that we understand it any better than we did decades ago.

Organisations, just like social entities, have cultures. These are referred to as organisational or corporate cultures. The culture of employee learning is, therefore, a subculture of the broad organisational culture which, according to Rebelo and Gomes (2011:173), is '...oriented towards the promotion and facilitation of workers' learning, its sharing and dissemination in order to contribute to organisational development and performance.' Likewise, Lim and Joo (2008) say that it is a culture characterised by the ability on the part of an organisation to create an environment conducive to the nurturing, acquisition and transfer of knowledge and modification of behaviour to reflect new competencies and insights. Senge (2006) and Jones (1996) conclude that the form of the 
culture of employee learning is manifested in the learning activities which employees at both individual and group levels participate in.

For Coetzee and Schreuder (2014), employee learning is broader than training as it goes beyond the mechanistic acquisition of pre-packaged competences and skills to engender values and attitudes which are necessary for employees to appreciate the importance of learning at all times. In other words, it is a much more holistic experience which is characterised by opportunities for collaboration amongst employees and on-going regeneration of knowledge through teams, networks, forums and communities of practice. In this regard, Hirschfeld and Field (2000) suggest a paradigm shift away from training to learning, a change of emphasis away from means to purpose, and a move away from conceptualising training as a stand-alone activity in organisations to perceiving it as an integral process which permeates all aspects of an organisation's culture.

Since employee learning influences job performance, its culture should be measured both in terms of tangibles and intangibles. While the former includes quantifiable deliverables, the latter include aspects which are not easy to quantify such as the cognitive and affective; capacity on the part of the employees to synthesise, analyse and evaluate information as well as readiness on the part of individuals and the collective to adopt positive attitudes towards learning (Marchington and Wilkinson, 2003). Characterising the culture of employee learning should also be constant reinforcement of, and reflection on, employees' levels of motivation for learning and their responses to the organisational employee learning project. Employees' biographies as well as the inter- and intra-group power dynamics and how these influence their learning are key aspects of this culture, as well (Clarke, 2005).

One of the implications of the characteristics of the culture of employee learning described above is that this culture is inherently layered. On this basis, Conner and Clawson (2004) caution that managers should focus less on trying to achieve specific business goals as some of these may be inconsistent with what is practically achieved at certain levels of the organisational hierarchy in terms of attempts to leverage learning for the attainment of those goals. Rather, they should focus more on cultivating a culture of learning, which is selfsustaining, that is, one in which employees are intrinsically inspired to learn both collaboratively and individually for the realisation of both individual and organisational goals. Debowski (2017: 66) confirms this when she says, '[t]he intrinsic motivation of the individual is a key predictor of a willingness to engage in learning and development.'

With respect to the discourse of employee learning, Fairclough (2007:23) argues that the term 'skill' and related vocabulary such as 'training' and 'competence' have normative, passive and objectifying connotations which imply the commodification of services such as education which ordinarily should not be associated with rhetoric that is individualistic and consumerist. Notwithstanding the importance of its content, context should therefore always be taken into consideration in the conceptualisation of employee learning and the culture characterising it. In addition, the relevance and value of the culture of employee learning needs to be continuously interrogated as they are not static but emergent phenomena. 
Although the concept of employee learning culture has not yet been widely researched, a distinction can be made between employee learning cultures which are weak and those which are strong. An organisation in which there is a strong culture of employee learning, is one where learning is not only promoted but also valued (Rebeleo and Gomes, 2011). This is done through, amongst other ways, '...a social process of sharing...' which places emphasis on people, accommodates the interests of all stakeholders and encourages collaborative sharing of knowledge (Rebelo and Gomes, 2011: 173). A weak culture of employee learning, in contrast, is one in which either the infrastructure and facilities for employee learning are non-existent; are not adequate or they exist but there is little or no support for employee learning by management and other stakeholders. As a result, a weak culture of employee learning is also characterised by apathy towards learning on the part of the employees.

Despite the need for a holistic conceptualisation of employee learning and the culture associated with it which is implied in the literature, as pointed out earlier, it continues to be practised on the basis of the one-dimensional view of government and employer initiatives, especially in South Africa (Vally and Motala, 2014). This raises the question as to how the other dimensions of employee learning need to be understood in order to initiate the requisite paradigm shift in terms of its practice. The notion of learning domains and reliance on critical realism, which are discussed in the next two sections, might be useful in this regard.

\section{Learning domains}

According to Bertram (2012), Bernstein's (2000) theory of the pedagogic device which was propounded in respect of the curriculum envisages re-contextualisation of knowledge produced at one site when it is transferred and reproduced at other sites. This produces three main fields, that is, the field of production, the field of re-contextualisation and the field of re-production. The field of production represents the site and processes whereby new knowledge which should be in the curriculum is generated (Singh, 2002). In the field of recontextualisation, some aspects of the knowledge from the field of production are selected, resulting in the production of pedagogic discourse (Ensor, 2004). In the official recontextualising field, those responsible for designing the curriculum choose the knowledge, pedagogy as well as the assessments that will make up the curriculum. On the basis of this, teacher trainers and authors of learner materials then interpret the curriculum in the pedagogic re-contextualising field. In the field of re-production, the teachers then take aspects which will have been selected into the curriculum and convert them into forms of knowledge which they then share with their students during classroom interactions.

This paper draws insights from Bernstein's (2000) theory of the pedagogic device as the theory suggests the possibility of knowledge produced at one site being transferred to another. The theory suggests the existence of inter-linked empirical fields within the education system in which different activities with a bearing on learning take place and can be investigated. Borrowing from these ideas, this paper conceptualises employee learning at 
the comprehensive South African university as taking place in three fields which I call domains, namely, the official, social, and pedagogic.

Constituting the official domain are the normative government and employer-initiated employee learning processes, policies and programmes. Examples would include the various pieces of legislation enacted by the government to govern employee learning and, at institutional level, the employee learning strategies and programmes. Found in the social domain are the employees' biographies; everyday lived experiences and the social relationships which they establish as they engage in work-related learning activities. Making up the pedagogic domain are the factors related to how employee learning is practically executed at the institution of higher learning. This is, for example, in terms of the content of the learning activities that the lower level employees are expected to participate in. In addition, it is in terms of the identity of the facilitators; the facilitation methodologies; where the learning takes place and the employees' responses to these factors. Linkages exist across the domains with, for example, the employee learning programmes and policies generated in the official domain being re-shaped, re-contextualised and re-produced in both the social and pedagogic domains.

\section{Critical realism}

CR prioritises the study of existence (ontology) over the study of the way knowledge is obtained (epistemology) (Layder, 1993). Vandenberghe (2014: 157) says CR is '...concerned with the reality of entities, generative mechanisms, deep structures and causal powers'. The paradigm therefore relies on investigating the causal forces responsible for events at different levels that make up the social world in an attempt to fully understand it (Khan, 2009; Crawford, 2010). In this paradigm, culture is defined as '...the set of ideas, beliefs, theories, values, ideologies and concepts which are manifest through discourses used by people at particular times' (Quinn, 2012: 28). Quinn (2012: 29) adds that in CR, '[t]he social world is understood to be comprised of the 'parts' (culture and structure) and the 'people' (agents)'. Agency is therefore about the individual and the choices and actions that he or she takes (Case, 2013). Its key aspect is thus the intentionality of the individual's behaviour which results in certain goals being achieved, in some cases inadvertently.

When individuals find themselves in certain structural and cultural contexts, the choices they make are determined by the constraints and enablements found in these contexts. How they do so is, however, a function of the collective and personal choices or powers (agency) which they bring to these contexts (Mingers, 2014). This shapes the architecture of the culture of the agents who are found in the given structures. This is in keeping with the view that in CR natural and social phenomena need to be looked at as a plurality of open, stratified, layered or differentiated system of objects (structures) which have causal powers (Morton, 2006). Borrowing from Marxist thinking, critical realists, therefore, assert that in a bid to understand and change the social world, the first step should be to identify the structures constituting it and analyse the historical and social contexts which generate events and discourses (Bhaskar, 1989; Hartwig, 2007; Quinn, 2012). In 
investigating the culture of employee learning, it is, therefore, necessary to look at the structural contexts in which it takes place and the agency which different role players are capable of exercising in those contexts to produce such a culture.

Jarvis (1992) suggests that there are basically two systems from which structures derive their agency. The first of these are the normative regulatory systems such as legislation and policies. The second are the informal systems which emerge from the interaction of agents with and within structures. In terms of employee learning, an example of such informal structures would be learning teams which themselves are a product of the common learning goals which employees in an organisation may be pursuing. The culture of employee learning is, therefore, also a function of how employees mediate the oftenconflicting interests of formally recognised agents and the informal ones (Drinkuth, et al., 2003).

\section{Conceptualising the culture of employee learning at a higher education institution}

Alluded to in the definition of the culture of employee learning in the literature is the need to avoid a narrow, linear, and deterministic conceptualisation of its form in any social context. This has been the pitfall of many studies on employee learning both in South Africa and globally (Coetzee and Schreuder, 2014). Drawing insights from Bernstein (2000), Bhaskar (1989), Quinn (2012), and Mingers (2014), employee learning at an institution of higher learning can be conceptualised as taking place in the official, social and pedagogic domains within which we find structures and agents that have an influence on the culture of this type of learning. Looked at this way, it can be concluded that, contrary to how it is commonly practised, in addition to being a function of government and organisational employee learning initiatives (official domain), it is shaped by what happens in the social and pedagogic domains. As a result, its form is also seen in how employees exercise their agency in response to the work-based learning initiatives which are initiated by the government and the employer. In investigating the form of this culture, it therefore becomes necessary to go beyond government and employer initiatives aimed at driving employee learning.

Rebelo and Gomes (2011) point out that the way in which employees respond to what happens in the official and pedagogic domains are, for example, characterised by social processes which encourage knowledge sharing and place emphasis on the intellectual and other personal assets which individuals bring to the learning situation. These also need to be unraveled if we are to come up with a holistic characterisation of this culture. Bordieu's (1986) notion of habitus on the basis of which it is proposed that human beings bring social capital to any learning enterprise which plays a mediatory role in the enterprise can also be drawn on to understand the inherently complex and multilayered nature of this culture. Figure 1 shows my conceptualisation of the various layers which constitute the culture of employee learning and the different levels at which questions aimed at establishing its form need to be asked. 


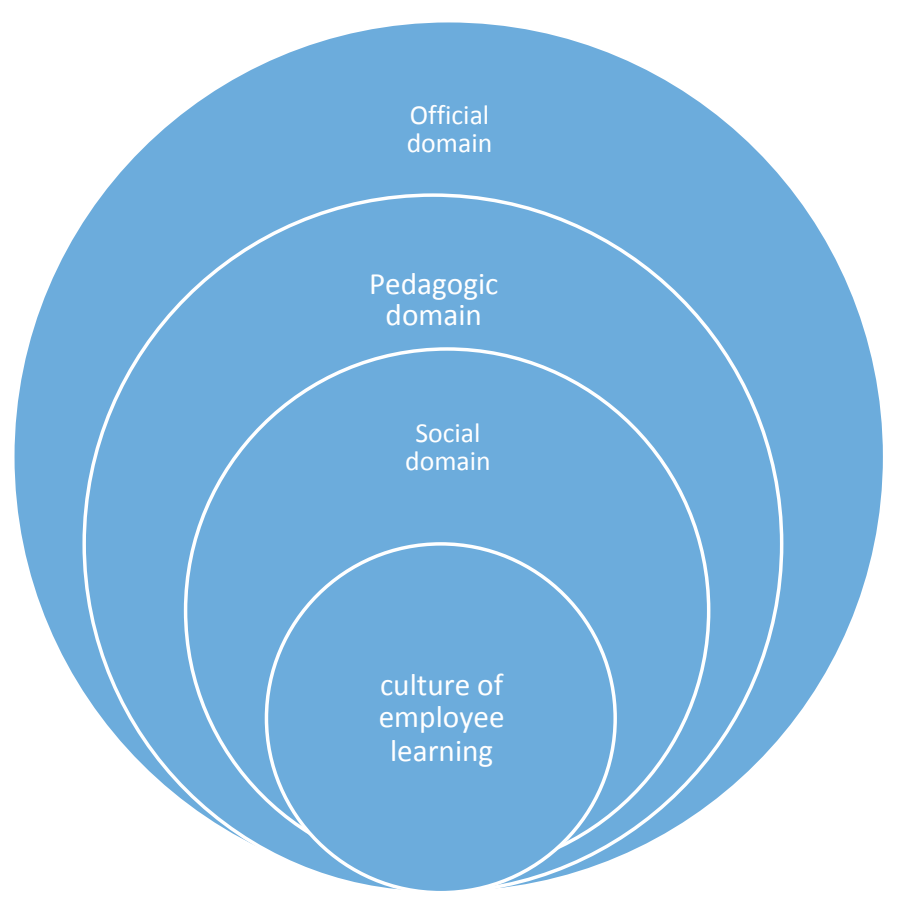

Figure 1: Conceptualising the culture of employee learning

\section{Implications of going beyond the official domain}

The discussion that follows is premised on implications of going beyond the official domain in the search for a holistic characterisation of the culture of employee learning at one of the universities in South Africa. As discussed earlier, this would entail investigating this culture at two other broad levels- the employees' social contexts (social domain), that is, their biographies and their experiences (pedagogic) in terms of actual participation in the employee learning curriculum at the institution. To give a holistic picture of my conceptualisation of the form of the culture of employee learning, the discussion, however, begins by exploring the data that may be sought from the structural and agential factors in the official domain of employee learning at the comprehensive university. This is then followed by a discussion of questions related to factors in the social and pedagogic domains.

Figure 2 is a more detailed version of Figure 1. It shows how the culture of employee learning can be conceptualised as being the product of the interface of the different structures and forms of agency which shape the culture of employee learning at the institution of higher learning across the different domains, that is, the official, social, and pedagogic. 


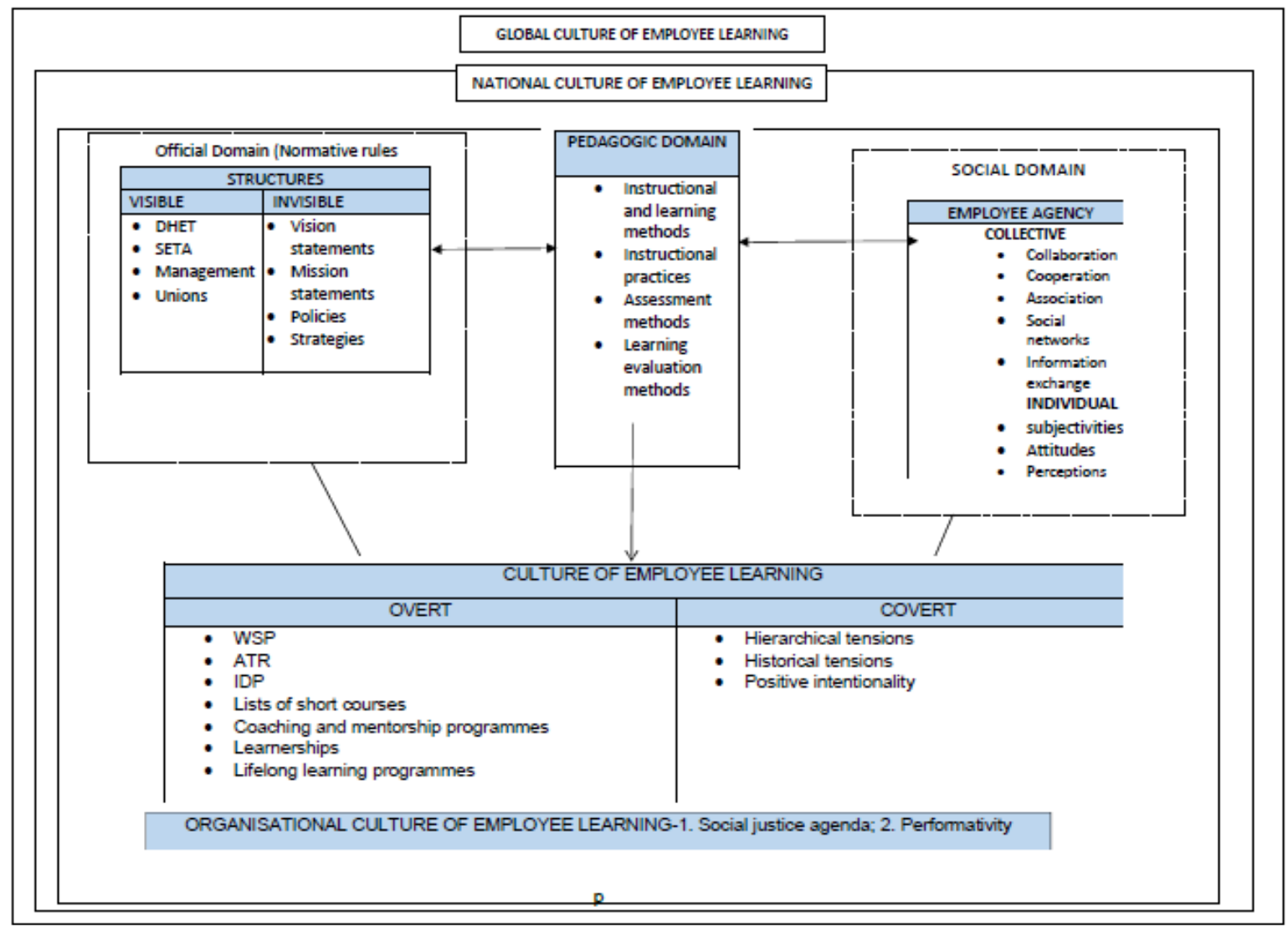

Figure 2: Domains of employee learning at a South African university (Adapted from Mavunga and Cross, 2017)

\section{Investigating the culture of employee learning in the official domain}

Using the notion of learning domains and CR, the official domain, as explained earlier and as shown in Figure 2, needs to be perceived as being made up of structures responsible for the normative rules, policies related to employee learning. Two categories of these structures, namely, the visible and invisible make up this domain. The visible structures are made up of easily identifiable entities such as the DHET (Department of Higher Education), the SETAs (Sector Education and Training Authorities), the University Council, the MEC (Management Executive Committee), the ELG (Executive Leadership Group ), faculties, departments, labour unions, and the HR Training and Development Unit. Making up the invisible structures are factors that are not very easy to identify unless one digs a little deeper than the surface upon entering the institution. Included in this category are national legislation governing employee learning such as the Skills Development Act, and the National Skills Development Strategy. The university's own employee learning policies and strategic thrusts can also be added to the category of invisible structures. Closely related with these structures are other structures such as the normative policies and programmes which are also overt and found in the official domain. Examples of these include the institution's ATR (Annual Training Plan), its WSP (Workplace Skills Plan), employees IDP (individual development plans), short courses offered at the institution, as well as learnerships and lifelong learning programmes. Other aspects of the policies would relate to what types learning programmes employees 
can take part in, how often they can do so as well as whether or not they receive financial support from the employer when they enrol for learning programmes offered by other institutions of higher learning and employee learning service providers. Constituting the culture of employee learning at the university, therefore, would be the beliefs and discourses around these structures (Quinn, 2012).

Taking the composition of the official domain as shown in Figure 2 and explained above, examples of questions which need to be asked include those focusing on the influence of national legislation such as the Skills Development Act and the Skills Development Levies Act on the culture of employee learning at the institution of higher education. In this regard, questions that must be asked are those to do with the influence of national employee learning strategies such as the National Skills Development Strategy 1- 3, as well as the White Paper on Post-School Education and Training, as well as that of the Sector Education and Training Authorities. Examples of such questions include, 'To what extent is the university compliant with the national legislation governing employee learning?' and 'To what extent is the university compliant with the recommendations of the National Skills Development Strategy 3?' At institutional level, questions that need to be asked are those seeking data about the content and influence of work-related learning policies and programmes in place at the institution. Examples of such questions include, 'Which workrelated learning programmes have you attended in the last twelve months?' and 'What is your evaluation of the work-related learning programmes which you have attended in the last twelve months?' Lastly, at the level of the institution questions that need to be asked must focus on the influence of the agency of structures such as the university's council, MEC, ELG, deans, heads of departments, as well that of unions which the employees are members of. An example of such questions could be, 'If you belong to a union, what would you say is the degree of influence of the union on your choice of employee learning programmes which you have attended in the last twelve months?'

\section{Going beyond the normative employee learning policies and programmes- focus on the social and pedagogic domains}

As explained earlier, I conceptualise the form of the culture of employee learning at the South African university as being layered, multi-dimensional, and extant in two other domains besides the official, namely, the social and pedagogic, as illustrated in both Figures 1 and 2. In order to come up with a holistic characterisation of the culture of employee learning at the university with respect to junior administrative and technical services employees, questions will also need to be asked around the factors that are found in these domains. Examples of such questions will be discussed in the two sub-sections which follow.

The conceptualisation of the influence of factors that are found in the social domain and pedagogic domains of learning is on the basis of Cope and Watts' (2000) assertion that simply putting in place employee learning structures, programmes and systems and declaring positive intentions, as usually happens when focus is only limited to the official domain, is not enough. Such an approach tends to be centralist-driven, sets rigid milestones, 
and, therefore, leads to deterministic outcomes. As Fejes and Nicoll (2008) further argue, such an approach leaves employee learning at the mercy of the government or employer. Yet, as discussed earlier, in reality, employee learning and the culture associated with it are also a function of other factors external to the official domain. This paper, therefore, suggest the need to go beyond the official domain in order to ask questions focusing on factors found in the social and pedagogic domains and how they shape the culture of employee learning at the higher education institution. As Betram (2012) asserts, looking at the different sites in which learning takes place enables the researcher to go beyond the normative policies and programmes to the question of how what is initiated in the official domain of learning is refashioned and re-contextualised in nuanced ways as the target learners engage with, and respond to it at different levels.

\section{Questions focusing on factors in the social domain}

Specific questions in the social domain which are important to ask should, for example, focus on areas such as the social relationships amongst lower level employees who do the same kind of work. So also are questions focusing on the relationships amongst these employees and other social groups both within and outside the institution and how these have a bearing on the employees' participation in work-related learning. Examples of these questions are, 'How often do you attend courses by the HR Training and Development Unit as part of a collective?' and 'To what extent do you collaborate with colleagues in your department, for example, on tasks given to you by course facilitators?' Also emerging from these relationships are forms of collective agency on the basis of which the employees respond to the employee learning project at the institution. This is important to pay attention to as there may be differences with negative or positive influences on how employees engage in workplace learning. On the basis of this, another relevant question to ask is, 'How do you use your association with colleagues in your department to express your views on the quality of the courses offered by the HR Training and Development Unit?'

In addition to collective agency, I perceive as existent in the social domain, a significant degree of individual agency which is also contributory to the form of the culture of employee learning at the university. This emanates from the influence of biographies, identities, self-direction, lived experiences, subjectivities and different levels of intentionality which individuals bring to the employee learning situation and thus shape the culture associated with it.

An investigation of the culture of employee learning at the university should, in my view, also conceptualise individual agency as being manifested in employees' career aspirations and levels of motivation to engage in employee learning. This is because individual agency is seen in the employees' perceptions of, and attitudes towards, different facets of employee learning at the institution. My interest in the mediatory role of individual agency is informed by Billet's (2006) view that paying attention to its critical role is necessary because it helps us to understand how aspects such as intentionality, subjectivity and identity in an individual's cognitive growth contribute to his or her ability to navigate the 
workplace learning landscape in spite of the influence of social factors which are generative of collective agency.

Gravett (2005) categorises the different forms of individual factors which influence the direction that people take when they engage in post-school learning into prescribed and felt needs. While the former are imposed by either government or organisations and are therefore extant in the official domain, the latter are unique to an individual. Felt needs have a very strong bearing on the individual's approach to employee learning and the culture associated with it as, ultimately, the choices which an individual makes and how they give effect to them are a joint function of their biographies, identities, motivation for learning and career aspirations. In this regard, examples of key questions which need to be asked are, 'What motivates you to participate in the learning programmes run by the university?' and 'To what extent do the learning programmes offered by the university fulfil your career development aspirations?'

Biographies play a critical role in influencing individuals' predispositions to workplace learning. Important questions to ask in this regard therefore include, 'Where were you born?', 'Briefly describe for me the type of family you were born in'; 'What would you say was the influence of your family on your attitude to work-related learning?', 'Which high school did you matriculate from?' and 'What would you say was the influence of your high school experiences on your current approach to work-related learning?' Examples of answers to these questions include those giving details on how families and schools might be said to have had a positive or negative influence on employees' current attitudes towards, and approaches to, employee learning.

My suggestion for the investigation of the employees' culture of employee learning in the social domain is also guided by Layder's (1993) research map as shown in Figure 3 according to which social phenomena can be analysed using a stratified or layered framework as suggested in CR. This framework consists of macro phenomena as exemplified by structural and institutional phenomena as well as micro phenomena such as behaviour and interaction. Whereas context is made up of the influence of macro-social aspects such as gender, national culture and the national economic situation, setting is made up of an individual's immediate environment, for example, the organisation or department in which they work. Situated activity is made up of the dynamics of an individual's face-to-face interaction with other individuals. Lastly, self has to do with how individuals are affected by social situations and their responses thereof. The individual therefore makes use of his or her own 'theories' and mental models to mediate these social situations. As a result, of interest to the researcher, should be the specific features of the social environment and how individuals respond to them. 
Element

\begin{tabular}{|l|l|l|}
\hline \multirow{2}{*}{ H } & CONTEXT & Macro social forms, for example, gender, national culture, national \\
\cline { 2 - 3 } S & SETTING & Economic situation \\
\cline { 2 - 3 } T & Immediate environment of social activity, for example, organisation, \\
O & SITUATED ACTIVITY & Dynamics of 'face-to-face' interaction \\
\cline { 2 - 3 } R & department, team \\
Y & SELF & Biographical experience and social involvements \\
\hline
\end{tabular}

Figure 3: Research map (Adapted from Layder, 1993:114)

Using this map, for example, in terms of context, pertinent questions to ask would, for example, be 'What is your nationality?', 'What national legislation related to employee learning are you aware of?' and 'To what extent would you say the national legislation governing employee learning contributes to employee learning in South Africa?' Although the focus of these questions is the official domain, guided by the intention to come up with a holistic characterisation of the culture of employee learning at the institution higher learning, it would be necessary to go a step further and ask questions related to other aspects of the map, that is, situated activity and self. In this regard, necessary to ask are questions focusing on the influence of structures such as churches and political organisations which the employees belong to and the mediatory role which these play in their responses to employee learning.

Layder (1993) further explains that situated activity focuses on the relationship between social involvement and interactions. The implication here is that there are elements of the interactions and processes which are a function of how the concerned individuals' behaviours inter-link and connect. This results in certain identifiable patterns which can be used as descriptors of the collective culture. It is, therefore, necessary to probe the nature of the relationships amongst different employees, for example, in respect of the influence of their strengths or weaknesses on their culture of work-related learning. On the basis of this, amongst others, questions which need to be asked are, 'Are you a member of a study group made up of colleagues in your department?' and 'What social factors motivate you to be part of a study group made up of colleagues in your department?'

\section{Questions focusing on the pedagogic domain}

As discussed earlier, found in the pedagogic domain are aspects such as the actual learning programmes in which the employees engage and how the employees respond to the influence of these aspects. In this domain, important questions to ask would be those focusing on the nature of the employees' interaction with the programme facilitators as well as their responses to these programmes. Other questions should focus on, for example, the types of tasks which require collaboration with their colleagues and what some of the 
specific details of this collaboration are. In addition, questions pertaining to the employees' perceptions of the effectiveness of the course facilitators, suitability of the facilitation methodologies, appropriateness of the courses to their work, as well as ease of use of the learning materials given during the courses would also need to be asked. In addition, questions need to be asked around artefacts and the material culture of the university related to employee learning in light of their centrality to efforts aimed at cultivating this culture. Examples of such questions include, 'How suitable do you find the training venues at the institution for the employee learning programmes which you have taken part in?' and 'How useful do you find the technological devices which you have to use as you take part employee learning programmes at the institution?

\section{Conclusion}

The paper sought to suggest a new approach to researching the culture of employee learning at a South African university. Drawing insights from Bernstein's (2000) theory of the pedagogic device which suggests that knowledge produced in one area can be transferred to another, the suggested approach is based on conceptualisation of the culture of employee learning as being layered and existing in three domains, namely, the official, social, and pedagogic. The paper conceptualises both the teaching and learning, as well as planning for them which take place in one domain as having a bearing on the teaching and learning which take place in the other domains. Given the existence of the three domains which the paper suggests, in researching the form of the culture of employee learning, it is necessary to ask questions which go beyond the normative employee learning policies and programmes which are found in the official domain. Examples of such questions in the social domain are those pertaining to the employees' biographies, identities, as well as how they exercise their individual and collective agency.

In the pedagogic domain, relevant questions to be asked are, for example, those focusing on the employees' actual experiences of, and responses to, the employee learning project at the higher education institution. The intention in going a step further to ask questions around factors found in the social and pedagogic domains in addition to the official domain would be to get data which would help to holistically characterise the employees' culture of employee learning. Also based on CR which concerns itself with the structure, agency, and culture interface, this would assist with the crafting of teaching and learning strategies in respect of employees who contribute to the realisation of the goals of universities through the critical work which they do. This would be a departure from the approach which has been taken in many studies on employee learning on the basis of which only factors in the official domain have been foregrounded. A shortcoming in this approach which is premised on HCT is that suggestions from these studies have, in the main, yielded top-down strategies characterised by misalignment between government and organisational employee learning strategies, on one hand, and employees' career development aspirations, on the other. In South Africa, this has tended to perpetuate racialised workplace inequalities which are, by extension, also responsible for the general socio-economic inequalities still 
prevalent in the country since the dawn of democracy in 1994. Research-based efforts to address this problem should therefore take into account the different domains in which employee learning takes place if such learning is to be meaningfully and effectively reshaped. These will assist with addressing challenges such as workplace and wider socioeconomic inequalities which are still prevalent in the country as well as the difficulties which many organisations continue to face in their attempts to realise their goals.

\section{Author Biography}

George Mavunga holds a PhD in Higher Education Studies. Currently he is a Senior Coordinator for the Extended (Management and Humanities) diploma programmes at the Academic Development Centre (ADC) at the University of Johannesburg in South Africa. $\mathrm{He}$ joined the University of Johannesburg from the University of Zimbabwe where he taught Communication Skills in the Department of Linguistics. His current research interests are in higher education teaching and learning; workplace learning and applied language studies.

\section{References}

Allais, S. \& Nathan, O. 2014. Skills? What Skills? Jobs? What Jobs?: An overview of research into education/labour market relationships. In Vally, S. \& Motala, E. (eds.) Education, Economy \& Society. Pretoria: University of South Africa Press, 103- 125.

Baatjes, B. 2014. Skills, Jobs and deception: Examples from the South African Workplace. In Vally, S. \& Motala, E. (eds.) Education, Economy \& Society. Pretoria: University of South Africa Press, 153- 170

Baatjes, I., Baduza, U. \& Sibiya, A.T. 2014. Building a transformative pedagogy in vocational education. In Vally, S. \& Motala, E. (eds.) Education, Economy \& Society. Pretoria: University of South Africa Press, 81- 102.

Bernstein, B. 2000. Pedagogy, Symbolic Control and Identity: Theory, Research and Critique. Revised Edition. Oxford: Rowman \& Littlefield.

Bertram, C. 2012. Bernstein's theory of the pedagogic device as a frame to study History curriculum reform in South Africa. Yesterday \& Today, 7: 1-11.

Bhaskar, R. 2008. A Realist Theory of Science. New York: Routledge.

Bhaskar, R. 1998. Facts and values: theory and practice. In Archer, M.S., Bhaskar, T., Collier, A., Lawson, T. \& Norrie, A. (eds.). Critical Realism: Essential Readings, London: Routledge, 409-43.

Bhaskar, R. 1989. Reclaiming Reality: A Critical Introduction to Contemporary Philosophy. London: Verso.

Bourdieu, P. 1986. The Forms of Capital. In Richardson, J.G. (ed.) Handbook of Theory and Research for the Sociology of Education, New York: Greenwood, 241-258.

Billet, S. 2006. Relational Interdependence between Social and Individual Agency in Work and Working Life. Mind, Culture and Activity, 13(1). 2006: 53-69.

Case, J.M. 2013. Researching Student Learning in Higher Education: A Social Realist Approach. London: Routledge. 
Clarke, N. 2005. Workplace learning environment and its relationship with learning outcomes in healthcare organisations. Human Resource Development International, 8(2):185205.

Coetzee, M. \& Schreuder, A.M.G. 2014. Careers- An Organisational Perspective. Cape Town: Juta.

Conner, M.L.\& Clawson, J.G. (eds.) 2004. Creating a Learning Culture: Strategy, Technology and Practice. Cambridge: Cambridge University Press.

Crawford, K. 2010. Influences on academics' approaches to development: voices from below. International Journal for Academic Development, 15(3):189-202.

Debowski, S. 2017. Developing Academics: The Essential Higher Education Handbook, New York: Routledge

Drinkurth, A., Riegler, C.H. \& Wolff, R. 2003. Labour Unions as Learning Organisations and Learning Facilitators. In M. Dierkers, M., Antal, A.B., Child, J. \& Nonaka, I. (eds.) Handbook of Organisational Learning and Knowledge. New York: Oxford University Press, 303-346.

Erasmus, B.J., Loedolff, P.v.Z, Mda, T.V. \& Nel, P.S. 2010. Managing Training and Development in South Africa. Cape Town: Oxford University Press.

Ensor, P. 2004. Legitimising school knowledge: The pedagogic device and the remaking of the South African school-leaving certificate 1994-2004. In The Basil Bernstein Symposium, University of Cambridge, July 2004.

Fairclough, N. (2007). Discourse and social change. Cambridge. Polity Press.

Fejes, A. and Nicoll, K. 2008. Foucault and lifelong learning: governing the subject. New York: Routledge.

Govender, V. 2009. Promoting a culture of learning and institutionalizing a learning organization in the South African public sector. Journal of Public Administration. 44(2): 364-379.

Gravett, S. 2005. Adult Learning: Designing and implementing learning events-a dialogic approach. Pretoria: Van Schaik.

Hamilton, S. 2014. (Re)claiming workers' education. In Vally, S. \& Motala, E. (eds.) Education, Economy and Society. Pretoria: University of South Africa Press, 230-243

Hameed, A. \& Waheed, A. 2011. Employee Development and its effect on employee performance: A conceptual framework. International Journal of Business and Social Science, 2(3): 224-229.

Harrison, R. 2009. Learning \& Development. London: Chartered Institute of People Development.

Hartwig, M. 2007. Dictionary of Critical Realism. London: Routledge

Hirschfeld, R.R. \& Field. H.S. 2000. Work centrality and work alienation: Distinct aspects of a general commitment to work. Journal of Organisational Behaviour, 21(7): 789-800.

Jarvis, P. 1992. Paradoxes of Learning: On becoming an individual in society. San Francisco: Jossey- Bass Publishers. 
Jones, S. 1996. Developing a Learning Culture: Empowering people to deliver quality, innovation and long-term success. London: McGraw-Hill Book Company.

Khan, P. 2009. Contexts for teaching \& the exercise of agency in early career academics: perspectives from realist social theory. International Journal for Academic Development, 14(3): 197-207

Layder, D. 1993. Understanding Social Theory. London: Sage.

Lim, T. \& Joo, B.K. 2008. The impacts of organizational learning culture and proactive personality on organizational commitment and intrinsic motivation: The mediating role of perceived job complexity. Midwest Academy of Management Conference, 3-12.

Marchington, M. \& Wilkinson, A. 2003. People Management and Development. London: Chartered Institute of Personnel and Development.

Matsumato, D. 1996. Culture and Psychology. Brooks: Pacific Grove.

Mavunga, G. \& Cross, M. 2017. The culture of employee learning in South Africa: Towards a conceptual framework. Journal of Education, 69: 303-326.

Mingers, J. 2014. Systems Thinking, Critical Realism and Philosophy: A confluence of ideas. London: Routledge.

Morton, P. 2006. Using critical realism to explain strategic information systems planning. Journal of Information Technology Theory and Application. 8(1): 1-4.

Msomi, S. 2011. Tell us about the SA you want-Manuel. Sunday Times, 12 June.

Naong, M.N. 2014. The impact of skills development training on lower level employees' motivation and job satisfaction: A case study of five South African companies. Mediterranean Journal of Social Sciences, 5(20): 369-380.

Noe, R. 2013. Employee Training and Development. New York: McGraw-Hill.

Quinn, L. (ed.) 2012. Re-Imagining Academic Staff Development: Spaces for Disruption. Stellenbosch: SUNPress.

Rebelo, T.M. \& Gomes, A.D. 2011. Conditioning factors of an organizational learning culture.' Journal of Workplace Learning, 23(3): 173-194.

Senge, P. 2006. The Fifth Discipline: The Art and Practice of the Learning Organisation. 2nd edition. London: Century.

Singh, P. 2002. Pedagogising knowledge: Bernstein's pedagogic theory of the pedagogic device. British Journal of Sociology of Education, 23: 571-582.

Buckler, C. and Creech, H. 2014. Shaping the future we want: UN Decade of Education for Sustainable Development (2005-2014). UNESCO. Available at:

https://unesdoc.unesco.org/ark:/48223/pf0000230302?posInSet=3\&queryld=5203d047 -9b10-4cd8-9794-8328d51f59b2 (accessed 21 October 2019).

Vally, S. \& Motala, E. 2014. No one to blame but ourselves: Rethinking the relationship between education, skills and employment. In Vally, S. \& Motala, E. (eds.) Education, Economy \& Society. Pretoria: University of South Africa Press, 1-25.

Vandenberghe, F. 2014. What is Critical About Critical Realism?: Essays in Reconstructive Social Theory. New York: Routledge 
Young, M. 2008. Bringing knowledge back in: From social constructivism to social realism in the sociology of education. London: Routledge. 